\title{
A study of tubal ectopic pregnancy based on the histopathology of fallopian tubes in the age group of 20-35 years
}

\author{
Meyur R. ${ }^{1}$, Sadhu A. ${ }^{2 *}$, Mondal H. ${ }^{3}$, Das R. ${ }^{4}$ \\ DOI: https://doi.org/10.17511/ijmrr.2020.i01.14
}

\footnotetext{
${ }^{1}$ Rudradev Meyur, Associate Professor, Department of Anatomy, R G Kar Medical College, Kolkata, West Bengal, India.

2* Anirban Sadhu, Associate Professor, Department of Anatomy, R G Kar Medical College, Kolkata, West Bengal, India.

3 Hironmoy Mondal, Assistant Professor, Department of Anatomy, R G Kar Medical College, Kolkata, West Bengal, India.

${ }^{4}$ Rupkamal Das, Professor, Department of Gynaecology and Obstetrics, R G Kar Medical College, Kolkata, West Bengal, India.
}

Purpose: Ectopic pregnancy is a life-threatening condition for the mother. Disruptions of the fallopian tube are considered to be important in its pathogenesis. The present study was conducted to observe the histopathology of this dreaded disease which could lead to the development of suitable remedies. Methods: Cases diagnosed with ectopic gestation in the fallopian tube who subsequently underwent salpingectomy were considered for the study. Histopathology of sections from the affected fallopian tubes was studied under the light microscope after staining with $\mathrm{H}$ and $\mathrm{E}$. Results: Most cases presented with amenorrhoea, whereas others had dysmenorrhoea, menorrhagia, and menometrorrhagia. Histopathologic findings included the presence of salpingitis (acute and chronic), calcification, sclerosed vessel and. Conclusion: Past history of inflammatory diseases, especially PID plays an important role in the subsequent development of ectopic pregnancy. Its prevention and treatment can lead to a decrease in the incidence of ectopic pregnancy.

Keywords: Ectopic pregnancy, Fallopian tube, Chorionic villi, Salpingitis, Trophoblasts

Corresponding Author

Anirban Sadhu, Associate Professor, Department of Anatomy, R G Kar Medical College, Kolkata, West Bengal, India.

Email: anir_sd@rediffmail.com
How to Cite this Article

Meyur R, Sadhu A, Mondal H, Das R. A study of tubal ectopic pregnancy based on the histopathology of fallopian tubes in the age group of 20-35 years. Int J Med Res Rev. 2020;8(1):92-96.

Available From

https://ijmrr.medresearch.in/index.php/ijmrr/article/ view/1148
To Browse

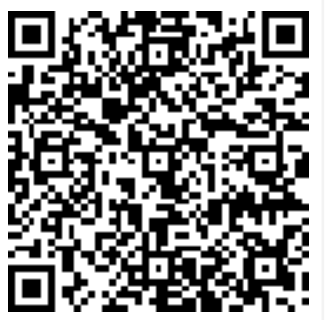

Manuscript Received 2020-01-20

Conflict of Interest No
Review Round 1 2020-01-30

Funding $\mathrm{Nil}$
Review Round 2 2020-01-04

Ethical Approval Yes
Review Round 3

Plagiarism X-checker $8 \%$
Accepted 2020-02-07

Note

() 2020 by Rudradev Meyur, Anirban Sadhu, Hironmoy Mondal, Rupkamal Das and Published by Siddharth Health Research and Social Welfare Society. This is an Open Access article licensed under a Creative Commons Attribution 4.0 International License https://creativecommons.org/licenses/by/4.0/ unported [CC BY 4.0]. 


\section{Introduction}

Ectopic pregnancy refers to gestation outside the uterine cavity. This type of gestation, however, cannot progress beyond the first trimester of pregnancy due to natural causes. It then presents with life-threatening features of hemorrhage and shock which at times is very difficult to treat. It is thus a serious cause of maternal morbidity and mortality accounting for $0.25-2.0 \%$ of all pregnancies [1]. $95 \%$ of ectopic pregnancies occur in fallopian tubes [2], with the majority occurring in its ampullary or isthmic portions [3]. The incidence of ectopic pregnancy in developed countries is about $19.7 / 1000$ pregnancies [4] and that in India is $3.12 / 1000$ pregnancies [5]. This serious condition has been studied by many authors in order to elucidate its underlying causes. Research worldwide has identified pelvic inflammatory disease (PID), abdominal-pelvic surgeries, ovulation-inducing drugs and intrauterine contraceptive device (IUCD) use as possible factors leading to this condition [6]. These predispose the fallopian tubes to diseases that hinder the natural progression of the fertilized ovum. The latter is held up in the fallopian tube leading to ectopic gestation. The present study, therefore, aims to ventures into the histopathology of tubal ectopic pregnancies in order to discover the abnormal changes located therein, such as congestion, fibrosis, hemorrhage, and inflammation.

\section{Methods}

The study was conducted as per the following details:

Setting: There was the active participation of investigators from the Department(s) of Anatomy, Gynaecology and Obstetrics and Pathology of R G Kar Medical College and Hospital, Kolkata. 73 patients were selected over a period of two years for the study. Detailed history along with uterine tube biopsies was collected from every case of ectopic pregnancy. The following criteria were strictly adhered to:

Duration: Two years

Type of study: Cross-sectional

Sampling methods: Random selection

Sample size calculation: the authors considered all patients on the basis of inclusion and exclusion criteria over the period of two years.

\section{Inclusion criteria}

01. a) Patients in the age group of 35-50 years

02. c) Salpingectomy for clinically diagnosed cases of ectopic pregnancy

03. d) Tubal ligation with or without MTP

\section{Exclusion criteria}

01. a) Patient refusal

02. b) Anatomically distorted fallopian tube (ruptured tubal pregnancy)

03. c) Patients with HBV, HCV and HIV infections.

Data collection procedure: Cases were selected based on the previously mentioned criteria. The following details were noted separately for each case: registration number, name and age, and address, parity, menstrual history (especially LMP), significant past history (contraceptive use, drugs, PID, surgery), symptoms suggestive of ectopic pregnancy (acute severe lower abdominal pain and bleeding per vaginum) and findings on general examination.

Urine was tested for pregnancy by strip kits. Blood was also tested for VDRL, HBsAg, HIV, HCV apart from complete haemogram. USG of the abdomen was also done. Gross examination of the uterine tube was done post-operatively and the length of each fallopian tube was noted. Each fallopian tube was inspected for products of conception, sterilization clip, rupture, cyst, nodule, tumor, and dilatation. Luminal occlusion, pus, placental tissue, and haemorrhage were also searched for. Fallopian tubes were sectioned at 3-5 mm intervals and tissues were then fixed in neutral buffered formalin [7]. A standard protocol was followed for preparing blocks from paraffin wax [8]. Serial sections from the blocks were obtained subsequently by rotary microtome [9], mounted on slides and stained with Haematoxylin and Eosin [10]. The final observation was done under low and high-power objectives of the light microscope.

Data analysis: data collected from the cases

Ethical consideration and permission: Prior permission from the Institution Ethics Committee was obtained. Individual consent was also obtained from each subject included for the study.

Scoring system: no scoring system was used for the study

Surgical procedure: Specimens of fallopian tubes were collected from the salpingectomy of clinically 
Diagnosed cases of ectopic pregnancy.

Parameters studied: Histology of mucosa, muscle, and serosa of different parts (intramural, isthmus, ampulla, and fimbria) of the fallopian tube.

Tools of study: Case history sheet, instruments for salpingectomy, preservative and container for specimen, chemicals for tissue processing, instruments and chemicals for block preparation, rotary microtome, instruments for slide preparation, chemicals for $\mathrm{H}$ and $\mathrm{E}$ staining and light microscope.

\section{Results}

Table 1: Presenting symptoms.

\begin{tabular}{|l|l|l|}
\hline \multicolumn{1}{|c|}{ Presenting symptoms } & Number of cases & $\%$ of cases \\
\hline Amenorrhoea & 07 & 09.58 \\
\hline Amenorrhoea with abdominal pain & 16 & 21.91 \\
\hline Dysmenorrhoea & 09 & 12.32 \\
\hline Amenorrhoea followed by dysmenorrhea & 33 & 45.20 \\
\hline Menorrhagia & 03 & 04.15 \\
\hline Menometrorrhagia & 05 & 06.84 \\
\hline
\end{tabular}

Amenorrhoea with dysmenorrhea was the predominant presenting symptom in 33 cases $(45.20 \%)$. Amenorrhoea is a single symptom or as a component of others (abdominal pain and dysmenorrhea) was present in $76.69 \%$ cases:

A) Amenorrhoea alone was present in 7 cases (9.58\%),

B) 16 cases $(21.91 \%)$ presented with amenorrhoea and abdominal pain,

C) Amenorrhoea followed by dysmenorrhoea was observed in $33(45.20 \%)$ cases.

Dysmenorrhoea, menorrhagia, and menometrorrhagia were present in $9(12.32 \%), 3$ $(4.15 \%)$ and $5(6.84 \%)$ cases respectively. Menorrhagia presented with the least cases. It is interesting to note that irrespective of these all patients had signs suggestive of acute blood loss progressing to shock - low blood pressure, feeble pulse with tachycardia and pallor on clinical examination.

Table-2: Light microscopy.

\begin{tabular}{|l|l|l|}
\hline \multicolumn{1}{|c|}{ Histopathology } & Number of cases & \% of cases \\
\hline Acute salpingitis & 31 & 42.50 \\
\hline Chronic salpingitis & 23 & 31.50 \\
\hline Calcification & 9 & 12.32 \\
\hline Sclerotic vessel & 7 & 09.58 \\
\hline Presence of trophoblasts & 3 & 04.10 \\
\hline
\end{tabular}

Acute salpingitis was the most common finding with 31 cases $(42.50 \%)$. Chronic salpingitis came next and was present in 23 cases (31.50\%). Calcification and sclerotic vessels were observed in 9 (12.32\%) and $7(09.58 \%)$ cases respectively. The presence of trophoblasts in fallopian tubes was observed in 3 $(04.10 \%)$ cases only.

\section{Discussion}

Amenorrhoea is a symptom or as a component of symptoms (amenorrhoea with abdominal and dysmenorrhea), that was present in $76.69 \%$ of cases. Amenorrhoea was reported in $84.7 \%$ of cases by Soren et al [11]. Rose et al and Pendse et al also reported similar incidences $[12,13]$. Ectopic gestation does not always present with a specific sign or symptom. The clinical picture depends on several factors. The extent of time taken for disturbance to occur in ectopic gestation is considered to be very important. A more extensive and rapid disturbance presents with a clearer clinical picture. Hence, ectopic gestation may present with menstrual irregularities and / or pain. Soren et al reported acute lower abdominal pain as the most common presenting feature in $97.2 \%$ of cases in their study [11]. It was present in $79.43 \%$ of cases in the present study. No history of pain abdomen seen in $20.57 \%$ of cases (amenorrhoea, menorrhagia, and menometrorrhagia) may be due to the undisturbed nature of tubal pregnancy or due to individual differences in the level of pain threshold. Pendse et al noted the absence of pain in $3.6 \%$ of cases [13]. Amenorrhoea was absent in $68.51 \%$ of cases in the present study. Oumachigui et al and Soren et al reported the absence of amenorrhoea in $23 \%$ cases and $15.3 \%$ cases respectively $[14,11]$. This wide variation regarding amenorrhoea is noteworthy. Cases in the present study may have had irregular menstrual cycles leading to a false impression of the date of onset of the last menstrual period. The latter may have lead cases to miss amenorrhoea and mention their menstrual irregularity (menorrhagia and metrorrhagia) as presenting complaints. Thus a large percentage of cases with the absence of amenorrhoea were observed in the present study. It should also be remembered that the socio-economic status of most of these cases prohibits them from seeking proper treatment for menstrual irregularities. Vaginal bleeding was present in $62.5 \%, 65.4 \%$, and $66.6 \%$ respectively in the study by Soren et al, Rose et al and Pendse et al respectively $[11,12,13] .10 .99 \%$ of cases presented 
With vaginal bleeding only in the form of menorrhagia and menometrorrhagia whereas $45.20 \%$ of cases had vaginal bleeding after amenorrhoea. Thus, overall $56.19 \%$ of cases presented with vaginal bleeding in this study. This is not very deviant from the previous studies. Kharat et al had opined that symptoms and signs of tubal pregnancy are the manifestation of tubal gestation which has been disturbed [15]. Since the classic picture of amenorrhoea, bleeding per vaginum, fainting attacks, abdominal pain, tenderness, and adnexal mass was present in only a certain proportion of cases they concluded that no specific sign or symptom can be said to be pathognomonic of ectopic gestation, but the combination of various findings may be slightly suggestive. Light microscopy revealed acute inflammatory cells in $42.50 \%$ of cases. Thus, acute salpingitis was the most common finding in this study. Dahiya et al reported acute salpingitis in $18 \%$ of cases whereas an intermediate value of $34.8 \%$ was reported by Kutluay et al $[16,17]$. The high incidence in this study may be due to pelvic inflammatory disease of sudden onset at the time of fertilization of the ovum in the fallopian tube. This could have led to abnormal implantation and subsequent progression to tubal ectopic pregnancy. Sharma and Bishnoi stated that the risk of ectopic pregnancy was known to increase seven times after an episode of acute salpingitis [18]. This fact may have contributed to such a high incidence of acute salpingitis in this study. Chronic salpingitis was the next common finding with an incidence of $31.50 \%$ in the present study. Lymphocytic infiltrate and fibrosis of the tube were observed. This is close to $39 \%$ reported by Dahiya et al in their study [16]. Dubuisson et al, Green et al and Persaud et al reported higher values in the range of $88 \%$ to $89 \%$ in their studies $[19,20,21]$. Sharma and Bishnoi reported $62 \%$ of cases with chronic salpingitis [18]. Kharat et al suggested that chronic infection due to sex life, use of intrauterine contraceptive devices, previous surgeries and lack of proper hygiene are linked to chronic pelvic inflammatory disease [15]. The lower incidence in this study as compared to acute salpingitis and some other studies may be due to the fact that some form of treatment could have ameliorated the inflammation to the extent that it has persisted as a chronic underlying one. Those cases who did not receive such treatment or had more severe infection displayed the histopathologic features of acute salpingitis. The latter cases were more in number in the present study. Calcification was observed in $12.32 \%$ and $7 \%$ of cases in the
Present study and that conducted by Dahiya et al respectively [16]. The latter authors were of the view that it represented the sequelae of some healed infection like tuberculosis. The higher incidence of calcification in the present study may be attributed to a greater incidence of past infections in patients selected for this study. Sclerosed vessels were observed in $9.58 \%$ of cases in the present study whereas Dahiya et al reported a closely similar value of $8 \%$ [16]. The presence of trophoblasts was observed in a minuscule of $4.10 \%$ of cases. The present study could not observe trophoblasts or any other product of conception in most cases. This definitely is a shortcoming of this study considering the fact that gestation was not confirmed by histopathology even though urine strip test indicated pregnancy.

\section{Conclusions}

The present study reveals that although amenorrhoea is the most common presenting symptom in patients of ectopic pregnancy, other menstrual irregularities like dysmenorrhea, menorrhagia, and menometrorrhagia should also be considered as indicators of the same, especially when there are signs and symptoms of acute loss of blood and/ or shock. This is important as clinicians mostly consider amenorrhoea to be the only presenting symptom of ectopic pregnancy. The histopathology strongly points to the fact that inflammation mostly due to infective agents plays an important role in the aetiopathogenesis of ectopic pregnancy. This is in concurrence with other studies conducted worldwide. A histopathologist is of immense value in identifying such abnormalities under the microscope as was done in the present study. Therefore diagnosis, management, and prevention of such agents is the need of the hour. Thus, early screening, prevention, and treatment can have a positive impact on this dreadful disease.

\section{What does the study add to the existing knowledge}

This study, therefore, provides them with additional clues to consider ectopic pregnancy in the differential diagnosis of patients presenting with menstrual irregularities and shock.

\section{Author's contribution}

Dr. Rudradev Meyur, Dr. Anirban Sadhu, Dr. Hironmoy Mondal, and Dr. Rupkamal Das, all 
The authors contributed equally in the preparation, conception, designing of the study and in the preparation of the manuscript.

\section{Reference}

01. Thonneau P, Hijazi Y, Goyaux N, Calvez T, Keita N. Ectopic pregnancy in Conakry, Guinea. Bull World Health Organ. 2002;80(5)365-370.

[Crossref]

02. Howkins and Bourne Shaw's Text book of Gynecology. 12th Ed- Publishers BI. Churchil Livingstone Pvt Ltd.

[Crossref]

03. Odendaal $H J$, Schaetzing $A E$, Kruger TK. Textbook of Clinical Gynecology. 2nd Ed, Juta Academic publisher, Cape Town, South Africa. 2001.

[Crossref]

04. Kamwendo F, Forslin L, Bodin L, Danielsson D. Epidemiology of ectopic pregnancy during a 28year period and the role of pelvic inflammatory disease. Sex Transm Infect. 2000;76(1)28-32. doi: [Article] [Crossref]

05. Mufti S, Rather S, Mufti S, Rangrez RA, Wasiqa, Khalida. Ectopic pregnancy- An analysis of 114 cases. JK Pract. 2012;17(4)20-23.

[Crossref]

06. Yadav A, Prakash A, Sharma C, Pegu B, Saha MK. Trends of ectopic pregnancies in Andaman and Nicobar Islands. Int J Reprod Contracept Obstet Gynecol. 2017;6(1)15-19.

doi: [Article] [Crossref]

07. Carleton HM, Drury RAB, Wallington EA. Carleton's Histological Technique. 4th ed, London- Oxford University Press. 1967;Ch 3;40-1.

[Crossref]

08. Carleton HM, Drury RAB, Wallington EA. Carleton's Histological Technique. 4th ed, London- Oxford University Press. 1967;Ch 4;57. [Crossref]

09. Carleton HM, Drury RAB, Wallington EA. Carleton's Histological Technique. 4th ed, London- Oxford University Press. 1967; Ch 5,78-85. [Crossref]

10. Carleton HM, Drury RAB, Wallington EA. Carleton's Histological Technique. 4th ed, London- Oxford University Press. 1967; Chapter 7, General Staining Procedures; 129.

[Crossref]
11. Soren M, Patnaik R, Sarangi BK. A clinical study on ectopic pregnancy. Int J Res Med Sci. 2017;5(11)4776-4782. doi: [Article] [Crossref]

12. Rose Jophy R, Thomas A, Mhaskar A. Ectopic pregnancy 5 years' experience. J Obstet Gynecol India. 2002;52(4)55-58.

[Crossref]

13. Pendse V. Ectopic pregnancy- a review of 110 cases. J Obstet Gynecol Ind. 1981;31;100-105. [Crossref]

14. Arora R, Rathore AM, Habeebullah S, Oumachigui A. Ectopic pregnancy- changing trends. J Indian Med Assoc. 1998;96(2)53-54. [Crossref]

15. Kharat D, Giri PG, Fonseca M. A study of epidemiology of ectopic pregnancies in a tertiary care hospital of Mumbai, India. Int J Reprod Contracept Obstet Gynecol. 2017;6(9)39423946.

doi: [Article] [Crossref]

16. Dahiya N, Singh S, Kalra R, Sen R, Kumar S. Histopathological changes associated with ectopic tubal pregnancy. IJPSR. 2011;2(4)929933.

[Crossref]

17. Kutluay L, Vicdan K, Turan C, Batioglu S, Oguz S, Gokmen O. Tubal histopathology in ectopic pregnancies. Euro J Obstet Gyncecol. 1994;57(2)91-94.

doi: [Article] [Crossref]

18. Pranshu S, Bishnoi R. Histopathological changes in ectopic tubal pregnancy. IJSR. 2018;7(2)2930.

[Crossref]

19. Dubuisson JB, Aubriot FX, Cardone V, VacherLavenu MC. Tubal causes of ectopic pregnancy. Fertil Steril. 1986;46(5)970-972. doi: [Article] [Crossref]

20. Green LK, Kott ML. Histopathologic findings in ectopic tubal pregnancy. Int J Obstet Gynaecol Pathol. 1989;8(3)255-256. doi: [Article] [Crossref]

21. Persaud V. Etiology of tubal ectopic pregnancy: radiologic and pathologic studies. Obstet Gynecol. 1970;36(2)257-263.

[Crossref] 